index @comunicación | no 10(2) 2020 | Páginas 35-53

E-ISSN: 2174-1859 | ISSN: 2444-3239 | Depósito Legal: M-19965-2015

Recibido el 20_03_2020 | Aceptado el 29_04_2020 | Publicado el 20_06_2020

\title{
¿POR QUÉ Y PARA QUÉ LA COMUNICACIÓN POPULAR? APUNTES SOBRE PUEBLO, SUBJETIVACIÓN Y POLÍTICA
}

POPULAR COMMUNICATION, WHY AND WHAT FOR? NOTES ABOUT PEOPLE, SUBJECTIVATION AND POLITICS

Moisés Valenzuela-Saavedra Instituto de la Comunicación e Imagen, Universidad de Chile mf.valenzuela.s@gmail.com https://orcid.org/0000-0003-3930-1620 
36

Resumen: Este ensayo se propone, con las limitaciones propias de quien analiza un fenómeno tan vivo, apuntar algunas ideas que ayuden a aclarar los alcances de la Comunicación Popular y la importancia que ella tiene como precondición de la actividad política. Para esto, se reflexiona sobre las nociones de pueblo y lo popular, los procesos de subjetivación y la relación que entre ellos establecen los ejercicios populares de comunicación, consideradas prácticas esenciales para sociedades que persigan ideales democráticos. El trabajo se basa en la idea de la Comunicación Popular como ejercicio conflictivo toda vez que, a través de la instalación de contradiscursos que hacen frente a una oficialidad comunicativa institucional, profesional e ideológica, se cuestiona la configuración del espacio público y se litiga con los procesos dominantes de identificación, permitiendo la existencia de desacuerdo y, en definitiva, haciendo posible la política. No se trata de una descripción de la Comunicación Popular, ni mucho menos de una enumeración de sus elementos constitutivos: más bien es un intento por defender el lugar que ella debe ocupar en nuestra vida en sociedad y en el espacio de lo común.

Palabras clave: comunicación popular; subjetivación; política; pueblo.

Abstract: This essay proposes, with the limitations of those who analyze such a live phenomenon, some ideas that could help to clarify the scope of Popular Communication and the importance of its political activity as a precondition. For this, it reflects about the notions of people and the popular, the subjectivation processes and the connection that between them set the popular communication activities, considering them essential practices for the societies to pursue their democratic ideals. This paper is based on the idea of Popular Communication as a conflictive activity whenever, through the installation of counter-speech that confront an institutional, professional and ideological communicative officiality, the configuration of the public space is being questioned and disputed with the dominant processes of identification, allowing the existence of disagreement and, in the end, making politics possible. It is not a description of Popular Communication, much less an enumeration of its constituent elements: rather it is an attempt to defend the place that it must occupy in our society and in the common space.

Keywords: Popular Communication; Subjectivation; Politics; People. 
Definir qué entendemos

por comunicación equivale a decir en qué clase de sociedad

queremos vivir.

Mario Kaplún

\section{Introducción}

Evidentemente hablar de Comunicación Popular exige que nos preguntemos por otras cuestiones previas que pueden resultar todavía más complejas. Por cierto, habremos de preguntarnos en este texto qué es el pueblo y por qué hemos decidido que de él derive el nombre de diferentes ejercicios comunicacionales no dominantes. También, en algún momento tendremos que problematizar la noción de espacio público y el rol que el pueblo tiene en él. Sin embargo, incluso antes de las reflexiones sobre lo popular, otro paso previo es necesario, porque de él depende todo el desarrollo de esta propuesta: no podemos hablar de comunicación, mucho menos de Comunicación Popular, si primero no aclaramos desde dónde entendemos la política misma.

En el Libro I de la Política, Aristóteles menciona que aquello que nos permite juzgar lo justo de lo injusto, nos diferencia de otros animales y, en definitiva, hace posible la política, es la palabra. Distinguida de la voz, que señalará únicamente sentimientos como el dolor y placer, la palabra:

[...] es para manifestar lo conveniente y lo perjudicial, así como lo justo y lo injusto. $Y$ esto es lo propio del hombre frente a los demás animales: poseer, él sólo, el sentido del bien y del mal, de lo justo y de lo injusto y de los demás valores, y la participación comunitaria de estas cosas constituye la casa y la ciudad (Aristóteles, 1988: 57).

De la propuesta de Aristóteles, dos cosas quedan más o menos claras, aunque cada una con consecuencias conceptuales diferentes: la primera es que la política, posibilitada por la palabra, tiene una naturaleza discursiva. La segunda, que el animal humano, en tanto poseedor de la palabra, tendría a su vez, y como resultado, una naturaleza política. Aunque esto parece tener un desarrollo lógico, un problema puede encontrarse en el intento de unir ambas dimensiones: si lo que permite la política es la palabra, y toda persona es capaz de palabra, se deja entrever una tendencia igualadora que otorgaría parte a cada individuo en las discusiones sobre lo público. El problema lo encontramos en que, si consideramos la política como una práctica esencialmente discursiva, casi por obviedad estamos hablando de un fenómeno relacional que no responde necesariamente a las condiciones naturales de las personas ni mucho 
menos reparte sus atribuciones o participaciones de forma igual. Es decir, tal como propone Arendt (2017), la política, lejos de ser una cualidad inherente a la condición humana, nace en el entre, lo que nos lleva a admitir que existe una configuración del espacio público que es construida intersubjetivamente a través del discurso, con todas las deformaciones, exclusiones y desigualdades que ello implica.

Queda entonces anulada la distinción por la palabra entre humanos y animales: más bien es una separación que diferencia del mismo modo a los humanos entre sí, toda vez que existen personas que, privadas del debate sobre lo común, sobre lo justo y lo injusto, son determinadas a la categoría de un ser únicamente fónico, es decir, como poseedor de voz, y no un ser lógico capaz de palabra, de logos. Sin embargo, en lo que hemos de darle razón a Aristóteles es en el rol predominante que juega la palabra en la actividad política. Ahora bien, donde es necesaria una reformulación es en su definición previa de la política misma, pareciendo más adecuado entenderla desde una perspectiva relacional, como actividad profundamente ideológica y no natural, toda vez que, como propone Ranciere (1996), la política trata de lo que vemos y su racionalidad está basada en la racionalidad del desacuerdo: hay política siempre que los incontados son capaces de desafiar la configuración actual del espacio público, reclamar su porción en él y subvertir el actual reparto de lo sensible (Ranciere, 2009).

Esta idea de reparto, Ranciere la define como el «sistema de evidencias sensibles que al mismo tiempo hace visible la existencia de un común y los recortes que allí definen los lugares y las partes respectivas» (2009: 9), es decir, es una fijación de tiempos, espacios y posiciones en lo común. Incluso Aristóteles, reconoce Ranciere, hablaba de la ciudadanía como el acto de tener parte en los actos de gobernar y ser gobernado. Sin embargo, el filósofo francés indica que el reparto de lo sensible responde a otra partición previa: la determinación de quién será apto para tener parte y quién no. Justamente aquí es donde la política adopta la racionalidad del desacuerdo: habrá política siempre y cuando los incontados sean capaces de desafiar un reparto dado y reclamar un lugar en lo común.

De este modo, la política tiene una matriz discursiva al ser posibilitada por la palabra. Pero un determinado reparto de lo sensible implica que no toda persona será capaz de palabra: existirán grupos que queden sentenciados al silencio o a la voz - sin posibilidad de palabra-, experimentando estas actividades únicamente desde los márgenes o en una categoría menor. Sobre esto, Bourdieu (2014) indica algo que nos es fundamental: aquellos hablantes más desprovistos de capital cultural quedan fuera de los mercados dominantes y 
tienen lugar únicamente en niveles privados, cayendo en la categoría de «lenguaje popular» (Bourdieu, 2014: 35).

La Comunicación Popular, entonces, no pertenece a los círculos de oficialidad: permanece en los márgenes, pues ahí es donde el pueblo suele destinarse a habitar. El espacio público, que ha definido su propio reparto, tiende a concentrarse en manos de discursos dominantes, conduciendo hacia un proceso de identificación y semejanza que anula la pluralidad - lo que precisamente para Arendt (2017) es lo propio de la política misma- y que no permite la cuenta de los incontados - lo que para Ranciere (1996) es aquello que la hace posible-.

¿Qué sucede con la Comunicación Popular entonces? Este ensayo se propone justificar cómo esta desafía un reparto de lo sensible dado, propicia la pluralidad, introduce la racionalidad del desacuerdo en el espacio público y, en definitiva, hace posible la política.

Antes de comenzar, no puede obviarse que el análisis se vuelve todavía más urgente considerando que en Chile, desde donde este texto se ha escrito, en octubre de 2019 fue desencadenada una movilización nacional que ha permitido, o por lo menos ha puesto en escena, la cuenta de los incontados: sectores marginados estructuralmente por un brutal neoliberalismo impuesto en dictadura han decidido manifestarse en todas las formas y modos posibles contra el estado actual de las cosas: rayados en casi cada muro del país, levantamiento de medios alternativos, performances en las calles nacionales y del mundo, numerosas páginas en plataformas digitales y registros personales viralizados... todas ellas iniciativas que, dentro de una larga lista, constituyen los recursos y prácticas comunicacionales de sectores de la población altamente apartados.

Esto, siendo en primer lugar una serie de actos movilizadores que remueven el escenario de lo público, confirma a su vez dos cosas de orden analítico: por un lado, que la apropiación del ejercicio comunicacional para el uso popular y comunitario, a pesar de que tiene antecedentes y puede rastrearse desde finales de los años cuarenta en América Latina (GumucioDagrón, 2001), maximiza sus posibilidades en la creciente tecnologización actual, permitiendo un nivel de observación, vigilancia y diálogo desde frentes no oficiales, subalternos, capaces de romper la distinción de seres fónicológicos al manifestar la condición de igualdad de sus participantes para debatir sobre lo común. Lo segundo que se confirma es que la Comunicación Popular puede, si así lo estima, alejarse del mediocentrismo acostumbrado y desbordar las plataformas tradicionales de comunicación, tal como propone Downing 
(2001) en Radical Media, quien entiende los ejercicios alternativos —o más bien radicales - no sólo en la utilización técnica de la radio, el video, la prensa o internet, sino también en manifestaciones que van desde el teatro callejero hasta los murales, la danza y el canto, haciendo notorio que la Comunicación Popular no necesariamente responde a las formas producidas por los mercados dominantes, sino que es capaz de agrupar todas las formas de expresión que, en su ejercicio, cuestionan un reparto determinado de lo común, de lo sensible.

Por cierto, a Chile se suman otros países como Ecuador, Honduras y Colombia -sólo por mencionar algunos casos-, que durante 2019 experimentaron manifestaciones similares, llegando incluso a especularse sobre una "primavera latinoamericana». Sin duda, este panorama obliga a repensar las maneras en que concebimos las discusiones sobre lo común, a poner atención en las irrupciones populares en la escena pública y a admitir que nuevas distribuciones de la palabra son posibles. Considérese esto como una de las motivaciones principales de este trabajo: el intento, esta vez, es por justificar la Comunicación Popular como condición de la política misma.

\section{2. ¿Pueblo?}

Hablar de Comunicación Popular remite, de forma inevitable, al pueblo. Pero ¿de qué hablamos cuando hablamos de pueblo? Para el francés Badiou (2014), existen al menos cuatro definiciones - de las que identifica dos como negativas y otras dos como positivas- desde las que podríamos obtener respuestas.

La primera definición corresponde a aquella que remite a una identidad cerrada, nacional o racial. Es decir, el «pueblo chileno», el «pueblo francés», el «pueblo mexicano». Esta concepción, como indica también García Canclini, tiene un carácter biológico-telúrico que entiende al pueblo como un «conjunto de individuos unidos por lazos naturales - el espacio geográfico, la raza- e irracionales - el amor a una misma tierra, la religión-, sin tomar en cuenta las diferencias sociales» (2004: 155), al mismo tiempo que establece los límites con aquellos que no tienen el derecho de ser parte. En definitiva, el concepto de pueblo como identidad remite a la idea de nación y afirma la relación privilegiada que un grupo guarda con el Estado (Khiari, 2014: 89).

Esta forma de entender al pueblo constituye para Badiou la primera definición negativa de pueblo. La segunda, muy de la mano de ella, es la que designa al pueblo oficial, que no es otra cosa sino la multitud de clase media capaz de voto de las democracias parlamentarias y que ha sido sometida por el Estado. El pueblo aquí es:

[...] el conjunto satisfecho de la gente de clase media, que se hace masa para que el poder de la oligarquía capitalista pueda ser considerado 
democráticamente legítimo, [...] una clase media libre de consumir los vanos productos con los que la atiborra el capital y libre de decir lo que quiere, también, mientras que ese decir carezca de todo efecto sobre el mecanismo general (Badiou, 2014: 16-17).

Las dos definiciones presentadas tienen como punto común su carácter excluyente. Sea una exclusión racista desde la identidad nacional, o una clasista desde la oficialidad, lo que sucede es que donde acaba la delimitación del pueblo comienza la afirmación de lo que a él no pertenece. Pero ¿se puede ser tan categórico y dejar fuera todo aquello que se ubica en el margen? Badiou se pregunta:

¿No existe también «pueblo» en el sentido de lo que, sin llegar a impulsar un desprendimiento unificado, no está realmente incluido, no obstante, en el dispositivo del «pueblo soberano» tal como lo constituye el Estado? (Badiou, 2014: 15).

Respondiendo la pregunta de Badiou, por supuesto que tiene sentido hablar de gente de pueblo toda vez que nos referimos a aquellos grupos que, tanto el Estado como la definición del pueblo oficial, han decidido dejar fuera de sus delimitaciones. Una de las tesis que alimenta este trabajo es precisamente esta: que en esa gente de pueblo también reside lo popular. En efecto, lo popular puede ser erigido en los bordes, tomando valor, por ejemplo, las propuestas de lo popular no representado, reprimido o ausente (Sáez, 2019).

Sáez, tomando la propuesta de Sunkel, define lo popular no representado como el «conjunto de actores, espacios y conflictos que son aceptados socialmente pero que no son interpelados por los partidos políticos de izquierda (o que no constituyen su objeto de interpelación principal)» (2019: 65), categoría en la que pueden incluirse mujeres, niños, jubilados, personas en situación de discapacidad, etc., y cuyos espacios suelen ser «la casa, las relaciones familiares, los servicios de seguridad social, el sistema hospitalario y los establecimientos de caridad pública» (2019: 65). Lo popular reprimido, por su parte, respondería a aquellos actores sociales que han sido relegados a los márgenes y que no son socialmente aceptados: delincuentes, alcohólicos, indigentes, en algunos casos todavía personas que no se identifican con el modelo sexual binario, etc., quienes se ubican en espacios como clubes nocturnos, centros clandestinos o plazas retiradas. Finalmente, la cultura popular ausente corresponde a aquel sector de la cultura popular que no ha sido reconocido o absorbido por la cultura de masas ni por la obrera.

Sin querer en esta oportunidad ahondar mayormente en estas distinciones, lo que se ha intentado evidenciar es que hay pueblo, mucho pueblo, donde terminan el pueblo oficial y las delimitaciones estatales. Precisamente desde 
aquí surgen las otras dos definiciones de Badiou y que nos interesan: la primera, desde un sentido histórico, reconociendo como pueblo a las formaciones sociales que preceden al Estado, y la segunda, estrechamente ligada a la anterior, del pueblo como lo excluido de la oficialidad y del Estado legítimo ya constituido. De estas dos nociones de pueblo se desprende la idea entonces de que el pueblo es una categoría política que opera desde los márgenes, que puja por el debilitamiento del Estado-nación al pelear por las condiciones que en su calidad de excluido le han sido negadas. El pueblo, desde esta perspectiva, alcanzaría su total sentido con la disolución final del Estado, tal como apunta Badiou: «Bajo la forma, transitoria, de la guerra de liberación nacional, o bien bajo aquellas formas, definitivas, de las políticas comunistas» (2014: 18).

Entonces el pueblo no seríamos todos ni todas por el hecho de compartir un territorio. El pueblo agrupa a los excluidos, a los marginales, a los socialmente no aceptados, y justamente allí, en esa partición de la nación, reside lo popular - $\mathrm{o}$ al menos es la definición que este ensayo adopta-, toda vez que considera, como Ranciere, que «el pueblo es la existencia suplementaria que inscribe la cuenta de los incontados o la parte de los sin-parte» (2006: 67).

Tal es la idea principal sobre el pueblo que da forma a la propuesta de este texto; sin embargo, no es posible continuar sin un breve comentario: el pueblo como categoría y también como sujeto político sigue siendo un terreno de disputa, lleno de heterogeneidades, de matices, y que se presenta como un concepto sobre el que no hay respuestas totales. No es posible, aunque quisiéramos, asumir una inherente vocación revolucionaria en él y apropiarnos de su destino, como tampoco podríamos eliminar su presencia en los espacios hegemónicos, ni mucho menos ignorar que en él existan rasgos de esa misma hegemonía. Adoptar una distinción tan marcada nos llevaría por un camino que, según Martín-Barbero (1987), analíticamente negaría el proceso histórico de formación de lo popular, que trata de un tipo de coexistencia y coproducción en el que resalta el sentido social de las diferencias, de la heterogeneidad, y que hace confluir dinámicas de exclusión, complicidad, dominación e impugnación.

A partir de ello, hay algunos riesgos prácticos y analíticos que podríamos asumir desde ya: que aquello consignado como popular - en este caso, los ejercicios comunicacionales atribuidos al pueblo- no ofrezca garantías como contenido libre de alienación (Araya, 2019), y que encierre en sí mismo la tendencia a parecerse a lo dominante (Kaplún, 1985). Sin embargo, aunque no hay duda de que estos reparos son fundados y tienen bastante sentido, tampoco es un callejón sin salida y este trabajo se permite proponer una: como se detalla más adelante, se sostiene que la Comunicación Popular no debe únicamente entenderse como el acto de habla, o el hecho comunicativo circunstancial visible 
en el espacio público, pues si así fuera, las inseguridades sobre lo popular estarían cada vez más cerca de ser posibilidades reales; en cambio, si pasamos a comprender la Comunicación Popular como un proceso de subjetivación política, toda vez que esto es una desidentificación del orden dominante y su identidad impuesta, habremos encontrado sus garantías: el proceso comunicativo popular implicaría, previamente, la afirmación de un nosotros y la revelación de un quién, cuestiones fundamentales para el proceso de desidentificación y la generación de disenso en el debate sobre lo común.

De todas formas, admitiendo que la diferenciación total entre lo popular y lo hegemónico es imposible, la alternativa frente a ello se reduce al acto de tomar posición, aun asumiendo la complejidad esencial que presenta el pueblo. En este sentido, considerando la propuesta de la subjetivación que será desarrollada, la decisión que toma este trabajo puede resumirse así: diremos que la Comunicación Popular, esto es, la comunicación que le es propia o tiene su origen en algún lugar de lo que hemos decidido llamar pueblo, es aquella comunicación de los sin-parte.

\section{Oficialidad y consenso}

¿Qué significa que la Comunicación Popular sea la comunicación de los sinparte? ¿Qué es aquello que les es negado? Si ya hemos adoptado una postura respecto a la noción de pueblo, con ello hemos evidenciado que por definición y consecuencia cualquier actividad que le sea propia, es decir, lo popular, será concebida en un orden marginal, cerca de los marcos oficiales, pero nunca dentro de ellos. La comunicación, lejos de escapar de este análisis, lo profundiza.

La oficialidad del pueblo implica casi por obviedad una oficialidad comunicacional que ha vuelto la actividad humana del habla un asunto de pocos. En un primer momento, diremos que esto comienza a configurarse mayoritariamente en dos grandes ámbitos: el de la institucionalización y el de la profesionalización de la comunicación. En el primero, se sitúa lo que Otero (1998) llama la comunicación como teoría: el surgimiento de los estudios en comunicación, las escuelas de periodismo y sus posgrados derivados, los sistemas de investigación, etc. En definitiva, los espacios académicos de producción intelectual y aquellos donde se forma la gente de la comunicación, que al mismo tiempo generan una gente que no pertenece a ella y cuyos actos de habla pertenecen al nivel popular. El segundo ámbito, nutrido por los egresados del primero, es el de la profesionalización. Este, al que Otero llama comunicación como ingeniería, agrupa a los llamados expertos en comunicación, es decir, publicistas, periodistas, analistas de campañas, audiovisualistas, etc., a los medios masivos y la prensa y a todo el sistema de mercado en el que se insertan. La noción de 
experto en comunicación, según Otero, refiere a «aquellas personas cuyo oficio consiste en el empleo de técnicas o procedimientos destinados al intento de producir cambios en las actitudes, las opiniones o las conductas de las personas» (Otero, 1998: 18), es decir, un profesional de las comunicaciones.

No obstante, la noción de oficialidad en comunicación se profundiza en otro nivel que resulta mayormente relevante: aquel que responde a cuestiones ideológico-discursivas que expulsan, todavía más, a los sectores populares del debate público. Veamos esto con un ejemplo: el aparataje comunicacional oficial en Chile presenta una concentración económica que tiene como consecuencia directa una concentración ideológica. Esto, aunque ha sido ampliamente revisado, hasta hoy se mantiene con mínimas variaciones. Sunkel y Geoffroy (2002) fueron algunos de los que evidenciaron que los vínculos empresariales que sostienen los medios en Chile han propiciado un monopolio ideológico; del mismo modo, Dérmota, también en 2002, hacía la siguiente descripción del panorama mediático nacional:

\begin{abstract}
Prácticamente no hay opiniones divergentes acerca del estado de la economía; ningún periódico hace un seguimiento analítico de los controvertidos sistemas de salud y de pensión; los indígenas, los trabajadores y los pobres, si es que llegan a ser retratados por los medios, lo son como populacho; los programas de televisión parecen haber sido censurados por el Vaticano; y las noticias carecen de análisis especializados, foros abiertos, interpretación y comentario; sólo hay cuatro géneros periodísticos: actualidad, reportajes, crónica y opiniones (Dérmota, 2002: 8-9).
\end{abstract}

La consecuencia inmediata de este escenario comunicacional es una tendencia marcada hacia la homogeneización del discurso y, como resultado, una identificación (opuesta a la subjetivación, como veremos) de lo público. Ahora bien, considerando las posibilidades económicas y tecnológicas con las que cuenta este «oficialismo», es posible pensar que la instalación de discursos unívocos y la anulación del disenso son inminentes.

Así, tal como existe un pueblo oficial que en sus afueras ubica un pueblo otro, existe una comunicación oficial que en sus afueras ubica una comunicación no legítima. Esto bien lo describe Bourdieu cuando asegura que estos hablantes, desprovistos de capital lingüístico, no se sitúan en las formas comunicacionales producidas por los mercados dominantes, teniendo como única forma de expresión el silencio o los intercambios familiares-privados, categorías que son excluidas a partir de las características de los hablantes y que entran, casi lógicamente, en el lenguaje popular.

Lejos de ser sólo una reflexión teórica, el sentido de traer esta distinción es evidenciar sus consecuencias práctico-políticas manifiestas en la 
desigualdad latente del espacio público, toda vez que consideramos que la existencia de personas legitimadas para comunicar, ya sea por su posición en el pueblo oficial, en la academia o el mercado, articula un grupo selecto y excluyente con acceso a plataformas exclusivas y oficiales de comunicación, aun cuando fuera de ese círculo toda persona sea capaz de palabra. Ser parte del pueblo oficial y/o de la gente de la comunicación conlleva una capacidad mayor de habla y de representación en el ámbito público, lo que funciona como una crítica directa a la utopía burguesa que evidencia Fraser (1993) cuando sostiene que esta perspectiva concebía lo público como un «teatro en el que la participación política es representada por medio del habla» (1993: 25) y que tenía la connotación de:

[...] una discusión racional sin restricciones sobre los asuntos públicos. La discusión debía ser abierta y accesible para todos: los intereses meramente privados eran inadmisibles; las desigualdades de estatus debían ser puestas entre paréntesis, y los que discutían debían deliberar como iguales. El resultado de este tipo de discusión sería la opinión pública en el fuerte sentido de consenso sobre el bien común (Fraser, 1993: 27).

La participación desigual en el ámbito público, entonces, obliga al fracaso de la concepción burguesa que otorga legitimidad al sentido consensual de la opinión pública y el bien común, aclarando que sólo responden a construcciones de grupos selectos y privilegiados con mayor capacidad de habla, cuestión que para Fraser simplemente es una apariencia de acuerdo, un «falso nosotros que refleja a los más poderosos» (1993: 40). Del mismo modo, Price identificó en 1992 que los riesgos discursivos del ámbito público son la dominación de las élites, la persuasión de masas o la tiranía de la mayoría, cuestiones que, en definitiva, junto al falso nosotros persiguen una dinámica totalizante, excluyente y consensual a través de la dominación, lo que tiene como consecuencia la anulación del debate discursivo del ámbito público.

Hemos dado aquí en el punto clave: la oficialidad del pueblo, junto a la oficialidad de la comunicación, tienen al final del camino un aparente consenso construido con base en la exclusión que es capaz de anular el debate mismo. La desigualdad es, aparentemente, una etapa transicional hacia la eliminación del desacuerdo. Esto, mucho más allá de significar el triunfo de algunos, es algo más profundo: un proceso de identificación que suprime el disenso y que, en palabras de Ranciere (2006), no es otra cosa sino el fin de la política. Esto puede ayudar a clarificar un malentendido de la democracia: cuando esta es pensada como el punto más alto y perfecto del consenso, simplemente estamos describiendo un proceso de identificación y dominación, donde un discurso ha 
logrado imponerse a todos los demás. Muy por el contrario, la democracia debe ser la garantía de desacuerdos y litigios, de la incorporación de los excluidos en el debate, de la admisión de la pluralidad. Pues si realmente la democracia pretende ser la forma de organización en la que el pueblo tome parte, el comienzo para ello debe ser la aceptación del conflicto. Esto no significa, en manera alguna, la eliminación del consenso: más bien es la garantía del disenso.

Entonces, ¿qué quiere decir que la Comunicación Popular sea la comunicación de los sin-parte? Lo que esto entraña es que esta, en tanto es el habla que surge de los bordes, introduce el conflicto en el espacio público, convirtiéndose en precondición de la actividad política toda vez que permite la existencia de contradiscursos a través de la apropiación, por parte de la gente de pueblo, del uso de la comunicación fuera de sus marcos institucionales-profesionales. Dada su doble posibilidad, es decir, como comunicación de aquellas personas marginadas de un orden social que establece un pueblo identitario-nacional oficial, y también de aquellas que están fuera de la gente de la comunicación, la Comunicación Popular es una alternativa de desacuerdo que, contra la identificación, permite la pluralidad y en sí misma es precondición de la actividad política. Dicho de otro modo, y como se trata a continuación, la Comunicación Popular es un modo de subjetivación política.

\section{Comunicación Popular: subjetivación y política}

«La esencia de la política», apunta Ranciere, «reside en los modos de subjetivación disensuales que manifiestan la diferencia de la sociedad consigo misma» (2006: 78). Por ello, la búsqueda de la igualdad de cualquiera con cualquiera es lo que Ranciere denomina política; no igualdad en tanto identificación, sino todo lo contrario: igualdad de convivencia de los diversos, de seres limitados a la voz que deciden demostrar junto a los demás su capacidad de palabra, su condición de seres también lógicos y no únicamente fónicos y, en definitiva, su rechazo a la idea de política como «manifestación de lo propio de una comunidad» (2006: 18) que convierte reglas particulares en reglas naturales de una formación social. Podríamos decir que en un sentido similar está la propuesta de Arendt cuando sostiene su idea de política en la pluralidad, en el «estar juntos y los unos con los otros de los diversos» (2017: 45), asegurando que el rompimiento de este principio, por ejemplo, en la constitución de cuerpos políticos con base en la familia, anularía la variedad originaria y llevaría a la ruina de la política.

En ambos casos estamos frente a una cuestión común: la eliminación de la diferencia y la totalización del ámbito público, esto es, la identificación, es la aniquilación de la política misma. La pregunta ahora es cómo lograr ir en el 
sentido contrario, o dicho de otra manera, cómo evitar la identificación y, derechamente, desidentificarse.

De Ranciere obtenemos la respuesta cuando afirma que un proceso de subjetivación es siempre uno de desidentificación o desclasificación. Pero ¿qué es esto que llamamos subjetivación? Para Ranciere es una heterología, una lógica del otro que nunca es la afirmación de una identidad, sino la negación de una identidad impuesta. Es el momento en el que los individuos se vuelven sujetos, cuestión que, dicho sea de paso, nunca sucede desde la genuina interioridad o desde el adentro, como diría Deleuze, sino que es posibilitada por el entre, por la relación de las singularidades. «¿Cuándo se es uno? A cada instante», sostiene Nancy (2017: 79), refiriéndose a la constante interacción y puesta en relación de la singularidad, a la exposición a otras singularidades y su contacto, al vínculo del adentro y el afuera que describe Deleuze en el tomo III de su Curso sobre Foucault:

[...] ¿qué es el adentro? El adentro es siempre el adentro del afuera. No es $m i$ interioridad. No hay ninguna restauración de una interioridad en Foucault en el sentido de mi interioridad. Hay simplemente un movimiento del afuera por el cual se constituye un adentro del afuera. Sólo el afuera tiene un adentro. Y esto es lo que Blanchot había comprendido muy bien a propósito de la Historia de la locura, cuando decía que lo que está encerrado es el afuera. A saber: sólo el afuera tiene un adentro (Deleuze, 2015: 24).

¿Qué es la subjetivación entonces? «Es la formación de un uno que no es un sí, sino la relación de un sí con otro» (Ranciere, 2006: 21), relación que al mismo tiempo es capaz de afirmar una resistencia a la identificación.

La razón por la que hemos llegado al concepto de subjetivación es la identificación que propone la dominación y anulación del debate público, es decir, la ilusión de un falso nosotros que se expresa como opinión pública y bien común y como aparente consenso impuesto por un pueblo oficial que excluye a lo que verdaderamente es el pueblo. Esta identificación, que tiene a su servicio un aparato mediático-comunicacional representado por sus niveles institucional y profesional ya mencionados, elimina toda posibilidad política en tanto es capaz de instalar relatos únicos e impedir la búsqueda de la igualdad como convivencia de los diversos.

Sin embargo, aquí es donde asoma la Comunicación Popular como un modo de subjetivación, una subjetivación política. Pero ¿en qué sentido la Comunicación Popular es uno? Si la subjetivación es el proceso relacional en que los individuos se vuelven sujetos, la subjetivación política es aquella que permite la revelación de un quién (Arendt, 2009) en la escena pública, de un actor 
capaz de irrumpir en el ámbito de lo común, y precisamente es en ese sentido que podemos comprender la Comunicación Popular como aquellos ejercicios que no sólo dan palabra a los que no la tienen y reduce las desigualdades discursivas del espacio público, sino que, aunque lo hace, previo a ello la Comunicación Popular es capaz de afirmar un nosotros, reclamar la posesión del logos por parte de los sujetos considerados únicamente fónicos y cuestionar el reparto de lo sensible generando disenso, permitiendo la existencia del debate mismo y, con ello, haciendo real la posibilidad de la política.

Por ello un ejercicio de Comunicación Popular no debe entenderse simplemente como el hecho circunstancial de comunicar, ni mucho menos en una relación indisoluble con el mediocentrismo. De una manera mucho más profunda, y tomando el análisis que hace Butler (2014) sobre la libertad de reunión, hemos de decir que el soporte de cualquier ejercicio de Comunicación Popular es una resistencia a la identificación desde el momento en que existe un encuentro entre singularidades capaces de afirmar un nosotros:

¿Qué clase de nosotros es este que se reúne en la calle y que se afirma a sí mismo a veces por medio del discurso, de actos o de gestos, pero más a menudo al reunirse en el espacio público como aglutinamiento de cuerpos visibles, audibles, tangibles, expuestos, obstinados e interdependientes? Aunque a menudo pensamos que el acto de habla por el cual nosotros, el pueblo, consolida su soberanía popular surge de dicha reunión, tal vez resulte más apropiado decir que la asamblea ya está hablando y realizando la soberanía popular. El «nosotros» pronunciado en el lenguaje ya se encuentra realizado por el encuentro de cuerpos, por sus gestos y movimientos, por su vocalización y sus modos de actuar en lo común (Butler, 2014: 41).

Este es el primer y más importante acto de habla presente en la Comunicación Popular: la reunión de los sin-parte que, desde el margen, han decidido levantar un contradiscurso en el espacio público. Es precisamente en este momento que la subjetivación, tal como apunta Ranciere, toma el carácter de tratamiento de daño y continúa su camino hacia la consecución de la igualdad de los diversos. Lo que hay aquí es un acto de habla, uno que, luego de decir «somos el pueblo», posibilita el disenso, permite la existencia del debate público y reclama su lugar en él. Así, lejos de ser circunstancial, lo que ocurre en la base de un ejercicio de comunicación popular es una reunión prolongada en el tiempo, que exige relación, conocimiento y organización, que acaba por ser un acto político que permite la subjetivación en la reunión de los sin-parte. Al respecto, Kaplún (1985) escribe:

La verdadera comunicación - dicen- no está dada por un emisor que habla y un receptor que escucha, sino por dos o más seres o comunidades humanas que intercambian y comparten experiencias, conocimientos, 
sentimientos (aunque sea a distancia y a través de medios artificiales). Es a través de ese proceso de intercambio cómo los seres humanos establecen relaciones entre sí y pasan de la existencia individual aislada a la existencia social comunitaria (Kaplún, 1985: 68).

Con este primer paso dado, es decir, el acto de habla afirmativo y la subjetivación del pueblo no oficial como tal —o una fracción de él一, lo que sigue es el ejercicio, el lenguaje surgido a continuación. Radios, periódicos, performances en la plaza principal de la ciudad. La manifestación comunicacional popular enunciada en el ámbito público, lejos de todo el aparato oficial y del mediacentrismo: el acto visible del disenso, el momento en que, como diría Mata, grupos históricamente marginados han logrado ir «del murmullo a la palabra» (2009: 21).

Esta materialización, acaso el ejercicio mismo que se sostiene en la subjetivación y la búsqueda de la igualdad tiene una naturaleza completamente diferente a la de los medios de comunicación tradicionales de alto alcance. Kaplún, tomando las ideas sobre educación de Freire, las compara identificando en esta última una dinámica «bancaria» de información, es decir, aquella que privilegia el «depósito» de contenidos en las audiencias - lo que sin duda lleva a lo que ya hemos detallado como identificación-, mientras que a la segunda, producida en, por y para las comunidades y el pueblo, le asocia como propia una vocación liberadora, que en los términos de este ensayo podríamos decir que también es subjetivante.

Gran parte de esto, Kaplún lo sintetiza de una forma excepcional cuando afirma que:

[...] los pueblos de hoy se niegan a seguir siendo receptores pasivos y ejecutores de órdenes. Sienten la necesidad y exigen el derecho de participar, de ser actores, protagonistas, en la construcción de la nueva sociedad auténticamente democrática. Así como reclaman justicia, igualdad, el derecho a la salud, el derecho a la educación, etc., reclaman también su derecho a la participación. Y, por lo tanto, a la comunicación [...] Los sectores populares no quieren seguir siendo meros oyentes; quieren hablar ellos también y ser escuchados. Pasar a ser interlocutores. Junto a la «comunicación» de los grandes medios, concentrada en manos de unos pocos grupos de poder, comienza a abrirse paso una comunicación de base; una comunicación popular, comunitaria, democrática (Kaplún, 1985: 67).

En definitiva, el valor de la Comunicación Popular, en cualquiera de sus formas, reside más o menos en este proceso: el reconocimiento del daño —o la exclusión de la oficialidad-, la afirmación de un nosotros y la subjetivación de los sin-parte - como tratamiento del daño-, la instalación de un contradiscurso, la posibilidad del disenso y, finalmente, la sobrevivencia de la política. 
50

\section{Conclusiones}

Lo que en este ensayo ha sido propuesto, tal como fue presentado, no atiende al propósito de describir la Comunicación Popular, sino a justificar su lugar en nuestras sociedades. Esta necesidad, si puede ahora llamarse así, parece urgente si tenemos en cuenta que hoy, a pesar de que los valores de la democracia no son abiertamente impugnados (Galli, 2013), es imposible negar el malestar que contra ella existe, acaso un anhelo de perfeccionamiento, motivado por profundas decepciones y desajustes. El diagnóstico que realiza Galli al respecto es preciso: a la democracia «se la invoca donde falta, y se la persigue con coraje como aspiración esencial de los pueblos, pero allí donde hace tiempo que está consolidada, sus instituciones van perdiendo su aliento vital» (2013: 11). Esta pérdida de fuerza se debe, entre otras cosas, a que la democracia se ha socavado a sí misma al permitir dentro de su institucionalidad los flujos de poder en modalidades contradictoriamente poco democráticas, más cercanas a un dominio oligarca por parte de las élites, lo que ha llevado sin duda al incumplimiento de una de sus intenciones fundamentales: la participación del demos. La democracia, advierte Galli, ha sido desbordada por las necesidades de la política actual, produciendo una insatisfacción que reúne el descontento por las promesas no cumplidas y la intuición de que no existen muchas alternativas más para pensar la administración del mundo.

Sin embargo, es este mismo malestar el que «constituye una ocasión para intentar entender lo que queremos decir con la palabra democracia» (Galli, 2013: 12), para iniciar un proceso de redescubrimiento, de refundación, o incluso de término de lo que hasta ahora conocemos como democracia. Considérese este texto una contribución a ello: a pensar una nueva forma de debatir sobre lo común en contextos donde las vías establecidas han encontrado su agotamiento, donde las discusiones han sido capturadas por unos pocos y donde es necesario posibilitar verdaderamente la actividad política; a pensar la democracia no como el punto máximo del consenso, sino efectivamente como el escenario donde debe producirse el disenso, el litigio, la confrontación entre hablantes.

No se entienda esto, por cierto, como el inicio de algo nuevo, pues con frecuencia es posible ver cómo distintos grupos y en múltiples formatos intentan comunicar desde veredas no dominantes. Pensemos algunos breves ejemplos: el colectivo feminista Lastesis, que tras realizar la performance «Un violador en tu camino» frente a un cuartel policial en Chile logró su traducción e interpretación en diversas partes del mundo contra la violencia machista; o los encuentros de «radios locas» realizados en Rusia, enmarcados en el Festival Hilo de Ariadna, donde es posible encontrar personas con diagnóstico 
psicopatológico que participan de la radiofonía como un acto terapéutico y político; y por qué no mencionar los diversos movimientos ecologistas que intervienen en las calles con el objetivo de cambiar de una vez nuestro modelo de desarrollo que acerca la naturaleza cada vez más al colapso.

Cada una de estas experiencias, entre muchas otras, indican que hay un proceso en marcha, una redefinición de la forma de expresarse en la escena pública: lo que nos queda es asumirlas, entenderlas como actividades fundamentales para la participación, sacarlas de una categoría episódica para incorporarlas como formas legítimas de discusión. Porque si la democracia $-\mathrm{y}$ diremos más específicamente, la democracia liberal- se ha desgastado, no puede ignorarse que el periodismo y las formas tradicionales de comunicación que le son funcionales también. Pensar el periodismo hoy como una actividad fiscalizadora del poder, que agrega sectores marginados, que es capaz de promover la igualdad en el espacio público, es todavía una ilusión más grande. No nos queda entonces algo más que pensar en las vías alternativas: no inventarlas, sino volver a mirarlas, considerarlas, entenderlas como actividad fundamental para la participación del pueblo en el debate público y para la sobrevivencia de la política. Porque lo que vemos en escena es un acto de habla, la expresión, el ejercicio específico de la comunicación; sin embargo, de lo que realmente estamos siendo testigos es del lenguaje que surge en las etapas finales de un proceso mayor, el que sin duda es precondición de la actividad política: la reunión de cuerpos, la afirmación de un nosotros otro, la revelación de un quién y, por último, recién aquí, la manifestación de esta cadena en el ámbito público, siendo un proceso completo que tiene que ver mucho más con la democracia que el acto mismo y puntual de comunicación. Si somos capaces de entender así las expresiones que irrumpen desde la no oficialidad en lo público, lograremos justificar todavía más la urgencia por admitirlas y comprender que es posible pensar nuevos periodismos.

Porque si mantenemos nuestra comprensión de las comunicaciones populares como un acto de habla circunstancial, estamos exponiéndolas al mayor riesgo que Kaplún reconoce en los ejercicios alternativos de comunicación, que no es otra cosa sino parecerse a lo establecido. Por supuesto, si no existe una base comunitaria, de autorreconocimiento, de relación entre un sí y otro, de una subjetivación como tratamiento de daño, es posible que eso suceda. En cambio, si detrás de la demostración episódica existe la afirmación de todo ello, lo que resulta es la política misma y con ello pueden acabarse los miedos que inscriben la Comunicación Popular, en tanto comunicación del pueblo, como un fenómeno que no puede librarse de la alienación. 
Tal es entonces la imperiosa necesidad de que exista Comunicación Popular, que debe ser alternativa y comunitaria, que sus procesos internos deben ser radicalmente distintos de cualquier ejercicio dominante - ahí es donde reside otra gran fuente de su valor, lo que puede ser sin duda motivo de otro trabajo, aunque bien ya lo hizo Kaplún en El Comunicador Popular-, que debe posibilitar siempre la existencia del desacuerdo y el conflicto, que nunca debe parecerse a lo establecido.

Quizás esto nos permita mirar los ejercicios populares de comunicación ya no con las asociaciones a precariedad y poco profesionalismo que suele hacerse, sino más bien como un elemento constitutivo del debate público y la democracia, la cual, como hemos intentado decir, debe avanzar en una vía totalmente contraria al consenso.

Para finalizar, dos preguntas parece que pueden ser ya resueltas:

¿Por qué la Comunicación Popular? Porque fuera del pueblo oficial está el pueblo verdadero, el ausente.

¿Para qué la Comunicación Popular? Para hacer posible la política.

\section{Referencias bibliográficas}

ARAYA, R. (2019). ¿Radio para los sin voz o radio para los sin voz pública? Media Development, 65(1), 32-35.

ARENDT, H. (2017). ¿Qué es la política? Paidós.

ARENDT, H. (2009). La condición humana. Paidós.

ARISTÓTELES (1988). Política. Gredos.

BADIOU, A. (2014). Veinticuatro notas sobre los usos de la palabra «pueblo». En A. BAdiou, J. Butler, P. Bourdieu, G. Didi-Huberman, S. Khiari y J. RANCIERE, ¿Qué es un pueblo? (pp. 9-18). LOM Ediciones.

Bourdieu, P. (2014). ¿Dijo usted popular? En A. BADIOU, J. ButLer, P. BourdiEU, G. DiDi-HubERMAN, S. KHIARI y J. RANCIERE, ¿Qué es un pueblo? (pp. 19-40). LOM Ediciones.

Butler, J. (2014). Nosotros, el pueblo. En A. BADIOU, J. ButLER, P. BOURDIEU, G. DIDI-HuBERMAN, S. KHIARI y J. RANCIERE, ¿Qué es un pueblo? (pp. 41-59). LOM Ediciones.

DELEUZE, G. (2015). La subjetivación. Curso sobre Foucault. Tomo III. Cactus. DÉRMOTA, K. (2002). Chile Inédito. El periodismo bajo democracia. Ediciones B Chile.

Downing, J. (2001). Radical Media. Rebellious Communication and Social Movements. Sage Publications. 
FRASER, N. (1993). Repensar el ámbito público: una contribución a la crítica de la democracia realmente existente. Debate feminista, 7, 23-58. https://doi.org/10.22201/cieg.2594066xe.1993.7.1640

GALLI, C. (2013). El malestar de la democracia. Fondo de Cultura Económica.

GARCÍA-CANCLINI, N. (2004). ¿De qué estamos hablando cuando hablamos de lo popular? Antología sobre cultura popular e indígena. Lecturas del Seminario Diálogos en la Acción. Primera etapa (pp. 153-168). Consejo Nacional para la Cultura y las Artes.

GUMUCIO-DAGRón, A. (2001). Haciendo olas: Historias de Comunicación Participativa para el cambio social. Plural Editores.

KAPLÚN, M. (1985). El comunicador popular. Ediciones CIESPAL.

KHIARI, S. (2014). El pueblo y el tercer pueblo. En A. BADIOU, J. BuTLER, P. BOURDIEU, G. DiDI-HuBERMAN, S. KHIARI y J. RANCIERE, ¿Qué es un pueblo? (pp. 89-104). LOM Ediciones.

Martín-Barbero, J. M. (1987). De los medios a las mediaciones. Gustavo Gili.

MATA, M. C. (2009). Comunicación comunitaria en pos de la palabra y la visibilidad social. Construyendo comunidades: reflexiones actuales sobre comunicación comunitaria (pp. 21-36). La Crujía.

NANCY, J. L. (2017). ¿Un sujeto? Ediciones La Cebra.

OTERO, E. (1998). Comunicación social. Editorial Universitaria.

PRICE, V. (1992). Opinión Pública. Universidad de Guadalajara.

RANCIERE, J. (2009). El reparto de lo sensible. Estética y política. LOM Ediciones.

RANCIERE, J. (2006). Política, policía y democracia. LOM Ediciones.

RANCIERE, J. (1996). El desacuerdo. Política y filosofía. Nueva Visión.

SÁEZ, C. (2019). El concepto de cultura popular ausente y su aplicación al caso chileno desde una perspectiva histórica. Comunicación y Medios, 28(39), 64-76. http://dx.doi.org/10.5354/0719-1529.2019.51121

SUNKEL, G. y GEOFFROY, E. (2002). Concentración económica de los medios de comunicación. Peculiaridades del caso chileno. Comunicación y Medios, (13), 135-150. http://doi: 10.5354/0719-1529.2011.12985 